Peer-Reviewed Article

ISSN: 2162-3104 Print/ ISSN: 2166-3750 Online

Volume 7, Issue 3 (2017), pp. 806-824

(C) Journal of International Students

http://jistudents.org/

doi: 10.5281/zenodo. 570035

\title{
Experience of Education in the International Classroom-A Systematic Literature Review
}

\author{
Jalal Safipour \\ Stig Wenneberg \\ Emina Hadziabdic \\ Linnaeus University, Sweden
}

\begin{abstract}
In this essay, we investigate the learning and teaching experiences in the international classroom from both the teachers and the students' perspectives. The findings of this study showed that language barriers are one of the difficulties, but academic cultural differences seem to play a more important role that can impact on the learning outcomes in the international classroom. This can also lead to negative experiences and the forming of stereotypical views of international students solely based on their educational background.
\end{abstract}

Keywords: Higher education, international classroom, international education, pedagogy, learning experience, teaching

Although war and socio-political conflicts are still major causes of migration, but new forms of population movement are emerging. Getting a higher education by experiencing what it is like to live abroad is considered to be a main cause of the population movement, comprising at least five million students around the world. According to the statistics, the number of international students has increased from 1.3 million in the year 1990 to 4.3 million in 2011 (UNESCO, 2013). It is estimated that this number will increase rapidly in the next few years (Sawir, 2013). The most popular destinations for international students are the United States and the United Kingdom (UNESCO, 2014). According to the United Nations Educational, Scientific and Cultural Organization (UNESCO), the majority of the students are from China and India. Therefore, it is important to explore international students and teachers who have diverse population experiences in the international classroom. 
Internationalization and the ability to attract international students is one of the main focuses of European universities and higher education policy in many countries (Van der Wende, 2001). In international higher education, a unique educational setting is established, called the international classroom, including host students, international students, and academic staff (Harrison \& Peacock, 2009). International students who study abroad usually attempt to increase their intercultural competence and cultural awareness during the course of their education (Akli, 2013). However, the overall experience of learning in the international classroom can be challenging if students (and teachers) are not prepared for the international education (Otten, 2003). One of the barriers that international students face during their education abroad is the language barrier (Poyrazli \& Lopez, 2007; Roy, 2013). English is the dominating language in the international classroom, which can be demanding for students who come from non-English speaking countries, and this may subsequently impact their learning outcome (Roy, 2013). In addition, several non-educational factors such as acculturation stress, self-esteem, social support (Jackson, 2013), discrimination (Poyrazli \& Lopez, 2007), and "micro-aggressions against language and race" (Jongyeon, 2013) can also have an impact on the educational experience abroad. A previous study showed that peerassisted learning (Bamford, 2008) and informed learning method (Hughes \& Bruce, 2013) can contribute to achieving the learning objectives of the international students. It was also revealed in another study that the academic staff's cultural awareness, with special regard to communications is essential for teaching in the intercultural classroom (Bamford, 2008).

One of the fundamental steps for improving pedagogical merit is combining theory and practice; thus, educational skills can be improved by considering environmental factors such as culture and diversity in order to maximize the learning outcomes (Elmgren \& Henriksson, 2014; Paris, 2012). Therefore, it is vital to investigate the education experience to be able to identify the barriers when it comes to teaching and learning. Accordingly, this study aims to investigate the learning and teaching experience in the international classroom, both from the students as well as the teacher's perspectives.

\section{RESEARCH METHOD}

A systematic literature review (Cooper, 2016) was carried out in order to identify the qualitative peer-review research articles that were published in scientific journals from 2010 to 2015. Qualitative articles were selected since the main focus of this study was to present the state of knowledge and to focus on important matters concerning the experience of teaching and learning in an international classroom. 


\section{Data collection}

All the data were gathered from the following databases: ERIC, PsycINFO, Science Direct, and Google Scholar. Articles with a qualitative approach, published in English, on learning and teaching in an international classroom (higher education) were included in this study. Exclusion criteria for selecting articles were quantitative studies, literature review studies, online education, articles older than five years, and articles that narrated the general experience of being abroad rather than having a specific focus on learning and teaching. Articles with no clear method and result section were also excluded in the later stage of the literature review search. Keywords used to conduct a search in the databases were: International classroom, exchange student, learning and education, teaching, pedagogy, qualitative research, and higher education.

\section{Selection process}

In total, 10,100 articles were identified in the first phase of the literature search. In the second phase, the search was limited to higher education and qualitative research, which reduced the number of articles to 965 articles. After removing any duplicated articles (331) and reviewing the title and the abstract of the identified materials so far, 104 articles remained that were subsequently read in their entirety. After carefully reading the articles' abstract, aim, and result section, the number of articles was further reduced to 29. Articles were excluded due to a lack of focus on learning and teaching in the international classroom, interventional or experimental studies, and studies about the acculturation process, as well as those dealing with the economic, social, cultural, emotional, or physiological challenges. The quality of the included articles was assessed by reading them in their entirety from the abstract to the conclusion section. All the articles were written clearly, and they described the method and result section in a clear and scientific manner.

\section{Data analysis}

A qualitative content analysis method was applied in this literature review study to synthesize the data, identifying and describing the patterns in order to provide knowledge and understanding of the area under investigation (Patton, 2014). For this purpose, all the included articles were reviewed carefully and the meaning unit identified, and on this basis relevant codes were created. In the final stage, the codes were grouped into sub-categories and categories.

Confirmability, credibility, and dependability were used to validate the findings (Patton, 2014). Quotations were used to approve the categorization in order to confirm confirmability. The first author conducted the analysis and established the sub-categories and categories, and the co- 
authors checked their relevance to confirm the credibility. Dependability was confirmed by careful descriptions of the method steps taken during the study.

\section{RESULTS}

In total, 29 articles were included in this study, and the study setting of four of the articles were Asia (India, Pakistan, Korea, and Thailand) and the rest belonged to Europe, North America, Australia, and New Zealand. The included articles in this literature review study explored the experience of teaching and learning in the international classroom from three perspectives: 1) International students, 2) Host students who study in international classrooms and, 3) academic staff who teach in the international classrooms. The results of this study were categorized into three main categories: 1) Language barriers and its challenges, 2) Impact of transferring to a new academic culture, and 3) Stereotypes and negative attitudes.

\section{Language barriers and its challenges}

This category refers to the language barriers and its overall impact on the teaching and learning experience in the international classroom (Brunton \& Jeffrey, 2014; Evans \& Stevenson, 2011; Janjua, Malik, \& Rahman, 2011; Khozaei, Naidu, Khozaei, \& Salleh, 2015; Kim, 2011; Kim., Tatar, \& Choi, 2014; Kumi-Yeboah \& James, 2014; Mukminin \& McMahon, 2013; Rienties, Johan, \& Jindal-Snape, 2015; Saravanamuthu \& Yap, 2014; Sheridan, 2011; Tait, 2010). The results indicated that language barriers are one of the main factors for: A) Excluding students from group discussion; B) Feeling of inequality; C) English grammar becomes the main focus of study and risk for plagiarism; and D) Knowledge translation barrier.

Exclusion from group discussion. Language barrier was one of the main factors that exclude students from group work and class discussions (Foster \& Stapleton, 2012; Yates \& Thi QuynhTrang, 2012). Students with low language proficiency were found to lose their confidence to talk freely even if they had good knowledge about the subject matter: "The language barrier is very important because if we cannot find enough words to talk, we will not be confident to talk” (Yates \& Thi QuynhTrang, 2012, p. 27).

As a result of the language barrier, students were not able to present their study task at a satisfactory level, thus, becoming disappointed about their performance:

I did my presentation and you know nobody knew what I was talking about... My big problem is I was not fluent in using English. So, the problems that I faced were [...] about using English (Mukminin \& McMahon, 2013, p. 8). 
According to the host students, international students usually sat and worked together and spoke in their own native language (Brunton \& Jeffrey, 2014; Harrison \& Peacock, 2010; Trahar \& Hyland, 2011). This can create difficulties when it comes to interaction and group work between the international and the host students: "This is gonna make us sound really bad. Sven was in our group and I wrote his section for him... we spoke about it without him and said, 'we're not letting Sven write this" (Harrison \& Peacock, 2010, p. 888).

Further, in some cases, the host students indicated that they did the whole work and just gave up on interaction and discussion: "A lot of the time you see it's one or two local students doing all the talk or even some of the local students are too hesitant to actually step up and say what they're thinking" (Cruickshank, Chen, \& Warren, 2012, p. 803). However, international students thought that the host students (native English speaking) did not consider their language barriers during the group discussion and generally spoke too fast (Kim, 2011). In order to reduce the negative impact of the existing language barriers, the academic staff used a variety of strategies such as giving a more thorough and clearer explanation of the course content. Another example was to apply different teaching tools (slides and written materials), specifically geared toward international students (Sawir, 2011). Speaking slowly also helped the international students to catch on.

I've learnt over these 20 years to speak more slowly and clearly, which I probably wouldn't have done if I had have just been teaching native English speakers for all of that time (Sawir, 2011, p 388).

Feeling of inequality. The international students had to put in more hours than the host students (English speaking students) due to the language barrier, for instance, in reading the study materials to understand them or preparing a presentation or writing their assignment in English (Brunton \& Jeffrey, 2014; Cruickshank et al., 2012; Wang. \& Byram, 2011).

Reading in English will be much slower, and sometimes I need to read four or five times in order to understand the main points (Wang. \& Byram, 2011, p. 412).

We are jealous with local students . . . they read so fast you know (Cruickshank et al., 2012, p 805).

This led to a feeling of inequality and dismay in the international classroom (Foster \& Stapleton, 2012; Kim. et al., 2014; Valdez, 2015). 
According to the international students' experience, they got lower grades (maximum C) since they could not properly express their understanding in written English (Tait, 2010). Fear of receiving an unfair grade (on the basis of the English skill and not actual knowledge) was described by one student as: "I was worried that my poor English would affect my presentation score while taking the Effective Communication class” (Kim. et al., 2014, p 451).

In addition, the international classroom was viewed as providing more opportunity for English speaking students since they could talk freely without fear of making grammatical errors or not finding the right words.

Lectures conducted in English are not carried out properly given the low level of students' comprehension and limited efficacy in improving students' English skill. Every single class is more like a show time for those who speak English fluently (Kim. et al., 2014, p 450).

According to the international students, this issue created an unfair learning environment for the non-English speaking students. In addition, when English speaking students talked about the subject matter and answered questions, it "sounded more academic" than when someone talked about an academic idea with broken English (Kim, 2011).

English grammar becomes the main focus of study and risk for plagiarism. Sometimes the main focus of the students with a language barrier was to memorize the proper English grammar in a text (Cruickshank et al., 2012) rather than focusing on the study topic itself, as one student says:

[I] try to memorise everything because it's in my second language. Sometimes understanding became less important than memorising. I try to use the original sentence from textbook in the exam rather than my own words because I think it looks better and will help to get more marks (Tait, 2010, p. 267).

Therefore, a language barrier can increase the risk of copying texts without referring to the original resources (plagiarism). Because the students cannot write in good English, they instead tried to copy the text: "We are not confident; if we write ourselves, we will be failed. We better copy other's views; copy other's sentences, so we memorize them” (Tait, 2010, p 269). Thus, it is important that international students receive comprehensive information to avoid issues of plagiarism (Davis, 2012).

Knowledge translation barrier. Teaching in English (in nonEnglish speaking countries) was also challenging for the teachers (Tange, 
2010). The teacher's teaching ability and being able to translate their knowledge was limited by their English language proficiency:

This will require my moving outside the terminology we have established, the words I used to describe the phenomenon in the first place. So it would end up as black talk, leaving them none the wiser (Tange, 2010, p143).

\section{Impact of transferring to a new academic culture}

Transferring to a new academic environment is challenging due to the different learning and teaching culture of the host country. Lack of understanding about the new education environment with different pedagogical approaches can heavily impact on the overall educational experience in the international classroom. These experiences were found with regard to two sub-categories: A) Learning style-Critical thinking and classroom participation vs. memorizing; B) Teacher centered learning vs. student centered education.

Learning style-Critical thinking and classroom participation vs. memorizing. Transformation from exam-oriented teaching to essay writing can be challenging (Khozaei et al., 2015; Sheridan, 2011) since writing academic essays is new for many international students (Janjua et al., 2011; Saravanamuthu \& Yap, 2014). Although language barriers play an important role here, it can also be attributed to not being familiar with the concept and practice of essay writing (Saravanamuthu \& Yap, 2014) or academic writing in general (Evans \& Stevenson, 2011). Even making logical scientific reasoning and formulating and structuring an essay can be different depending on the native academic culture of the international students:

I think the cultural difference, the way we express ideas - the logic is different. I think English is very straightforward... But in Chinese the logical is different, we just tell you maybe the background and then the story and the end will be a circle to work out whole story and then you work with the end (Evans \& Stevenson, 2011, p. 6).

Writing style and educational culture go hand to hand, and possible misunderstandings with regard to plagiarism can arise from this difference, in addition to the language barrier mentioned earlier (Tian \& Lowe, 2013). For example, some international students mentioned that they had been trained to write freely in their home country, but with the caveat not to question any previously established knowledge: "good student must not question authorities, but faithfully copy and reproduce them” (Tian \& Lowe, 
2013, p. 590). It was also important for them to write freely without citing any references in the actual text:

I worked on my undergraduate dissertation, it was totally different. We wrote freely. We were only required to list references at the end of the essay rather than at very place of citation within the writing. My undergraduate dissertation is full of direct quotation of books or articles without any references... (Tian \& Lowe, 2013, p. 590)

On the other hand, some students gave priority to the exam-oriented teaching style with respect to understanding by memorizing: "I think taking exams is very important, because it urges you to do revisions constantly. And this repetition helps memorisation and understanding" (Wang. \& Byram, 2011, p 412). While in transition to the new academic environment, the priority shifts to the critical thinking and problem solving method by writing academic papers, and participating in classroom and group discussions (Gram, Jaeger, Liu, Qing, \& Wu, 2013; Hughes \& Bruce, 2013; Janjua et al., 2011; Kim, 2011; Tange, 2010; H. Tange \& Jensen, 2012; Tian \& Lowe, 2013; Wang. \& Byram, 2011).

In the international classroom, some students do not participate in the group discussions since they are used to engaging in different learning styles in their home country (Foster \& Stapleton, 2012; Mukminin \& McMahon, 2013). Based on their previous experience, the students do not express their knowledge in the classroom since the good student is the one who "listens and takes notes" (Mukminin \& McMahon, 2013). It was also mentioned that students prefer to stay quiet when they deal with easy study topics:

When the professor asked a question, I did not answer him because I thought he was asking too easy of a question. However, other American students answered him with very simple and basic answers, and the professor praised their answer as if it were the greatest answer (Kim, 2011, p. 290).

It seems that students do not get enough information about the educational practices in the host country (Kim, 2011). Lack of knowledge about a new academic culture can lead to confusion and feelings of dissatisfaction with the whole study program and classroom activities:

I don't know why they like presentations or group discussions. I don't really learn from those kinds of activities. I think it is a waste of time. When other students presented in the classroom, I was thinking about something else. When I present in the classroom, I 
don't think others will truly care about what I am saying (Kim, 2011, p. 286).

Not being familiar with the new academic culture could exclude the students from the classroom discussions (Foster \& Stapleton, 2012; H. Tange \& Jensen, 2012), similar to the impact of language barrier discussed previously. Active participation in group discussions requires a critical thinking approach, which can be very difficult for some students:

They would like you to criticize others, to say what is wrong with this theory and what is wrong with that, then give your own opinion. I find it very difficult, but you have to follow their way. We are accustomed to commenting on a theory favorably, not critically or negatively, so, we are not used to this way yet (Wang. \& Byram, 2011, p. 418)

Vice versa, understanding the differences of an educational system and implementing measures to promote a positive educational experience could contribute positively to the learning process (Kumi-Yeboah \& James, 2014), English practice (Valdez, 2015), and integration of international students into the new academic atmosphere:

The classroom atmosphere is different and free, you can talk, present your ideas freely even without raising your hand. The knowledge within this kind of open communication helped me to understand different ideas and perspectives. In my country, students only listen throughout the class, keep your questions, due to this differences, I think classroom discussion has changed my perspectives (Kumi-Yeboah \& James, 2014, pp.45-46).

However, teachers have also indicated that they struggle in the international classroom and in their interactions with international students (Tange, 2010).

Teacher centered learning vs. student centered education. Another main challenge was moving from teacher-centered educational system to student-centered education (Evans \& Stevenson, 2011; Foster \& Stapleton, 2012; Tian \& Lowe, 2013; Valdez, 2015; Wang, 2012; Yates \& Thi QuynhTrang, 2012). In teacher-centered education, the teachers are mainly responsible for providing knowledge, and the student's learning style is more passive, while in student-centered education students take more action and responsibility for the learning process: 
In my country... your supervisor would tell you what to do, but here it's different, so I'm kind of like waiting for my supervisor to tell me what to do, but my supervisor is waiting for me to tell them what I'm going to do (Evans \& Stevenson, 2011, p. 6).

This can create obstacles with regard to the student-teacher interaction since these students are not supposed to closely communicate with their teachers because of the traditional way of giving and showing their instructors (too much) respect (Evans \& Stevenson, 2011; Mukminin \& McMahon, 2013; H. Tange \& Jensen, 2012).

I was still afraid of asking professors [questions] or visiting their office, whether it would be fine or not to email them (Mukminin \& McMahon, 2013, p. 9).

Conversely, in the new academic environment, the students realized that they increasingly have to work more independently and communicate more freely with the teachers and even criticize them:

I kept asking the tutor questions whenever I met problems... a comment says what I have discussed is outdated....His response, out of my expectation, is 'feel free to disagree' So surprising. He says I could insist on my idea as long as I can support it. So surprising, we are allowed to challenge the teacher (Tian \& Lowe, 2013, p. 252).

Pedagogical and communication issues identified by teachers as being cultural in origin can be improved by using different interventions such as talking to them after class or trying to start a conversation with them at any given time:

I never got any e-mails from students asking about anything outside the lesson. But I forced myself to talk to them after class.... I got the coffee and sat in the middle of the group whether they like it or not (Kerdchoochuen, 2011, p. 12).

One of the main tasks for teachers in the international classroom is to approach these students and build a professional relationship with them in order to create a more participatory education environment:

It is obvious that they perceive me as the professor and their relationship to me as different. And they may say that they are not used to professors who will talk with them. And really, this is also 
an important part of week 1, that they discover that I am a person who takes an interest in them (Tange \& Jensen, 2012, p. 187).

\section{Stereotypes and negative experiences}

Based on what has been mentioned earlier about language barriers and academic cultural differences, teachers and students who participate in the international classroom may generalize their experience with regard to some specific students and their respective country of origin, or harboring a negative attitude and questioning the feasibility of the international classroom.

Due to the previous unpleasant teamwork experience, negative attitudes have been reported with regard to working with international students (Valdez, 2015). Host students have experienced that the behaviors of some international students are viewed as "excluding.” For instance, they tend to not socialize with others, talk in their own language instead of English, and always stay together "folk-together," (Harrison \& Peacock, 2010). It is interesting to note that these feelings of exclusion likewise is experienced by international students when there is no "mixture" of international and host students (Sheridan, 2011).

Another factor that may be related to negative attitudes and stereotypical views of international students is manifested in the occurrence of plagiarism (Valdez, 2015). Academic staff had negative experience in this area, which in the end could lead to a negative attitude: "All the most serious examples of plagiarism that I personally have come across have been from international students" (Davis, 2012, p. 29). However, in most cases the term "international students" was used only in reference to students from "South East Asia and Africa" (Davis, 2012). Categorizing students in this way and giving higher value to the western style of education was also mentioned as "Pre-modernist" and "post-modernist" students (Sawir, 2011).

Whereas in fact the West is very proud of its success, scientific success and knows that it comes from the epistemology and the ontology that underpins that, and to modify that to meet the expectations of pre-modernist or non-modernist students is to take a step backwards in terms of that enlightenment project. So universities aren't prepared to do that and, we aren't really allowed to do that and you can understand why (Sawir, 2011, p. 358).

Nevertheless, the students try to cope with the new academic culture during their overseas education (Evans \& Stevenson, 2011; Hughes \& Bruce, 2013; Kumi-Yeboah \& James, 2014; Tian \& Lowe, 2013). Unfortunately, some lost their own academic identity in this process, and 
some even asked to change their own personal identity. For example, some students found it offensive when teachers "mispronounced" their name or even asked them to use an easier name (Kim, 2011). In an effort to overcome this negative experience, one student made it clear how the teachers should pronounce his name: "Hi, My name is Jung-Hun. Don’t call me 'Jung' or 'Hun' or 'Hun-Jung.' If you call me 'Jung,' it is the same as if I called Brian as ‘Bri’ or ‘Ian,’ Isn’t that awkward?’ (Kim, 2011, p. 289).

\section{DISCUSSION}

The results of this study revealed that teaching and learning in the international classroom can be challenging for the host and home students and also for the teachers. These challenges can be due to language barriers and academic cultural differences that can lead to negative experiences and/or a stereotypical view of certain student populations. In the international classroom, the learning and teaching language is English. In this environment, non-English speaking students are usually hard at work to overcome the language barrier, while they also need to understand the study subject itself and achieve the learning goal/s.

Besides the language barriers, entering a new academic environment can be confusing for many students (Kennedy, 2002). In most cases, western universities offer courses and programs in English that international students can apply for. Still, encountering unknown pedagogical methods can marginalize students who are not familiar with this new educational environment. In western education policy, the priority is placed on "independent and critical thinking," "identifying problems and problembased learning," “interpreting information," "developing and communicating knowledge," while many international students come from the learning culture environment where the priority is on "memorizing and understanding" and "reproducing information" (Eaves, 2011; Elmgren \& Henriksson, 2014; Kennedy, 2002; Tavakol \& Dennick, 2010; Valiente, 2008).

These two different ways of conceiving and experiencing learning are quite similar to the description of Marton \& Booth (1997). They summarize six conceptions of learning into two main groups: "Learning as primarily reproducing" and "learning as primarily seeking meaning”. Being aware of this sort of difference in educational cultures may help both students and teachers to facilitate the learning process in the international classroom (Marton \& Booth, 1997).

The results of this study also indicate that in the international classroom some students are not engaged in classroom discussions or they do not actively participate in group work. This lack of participation can be explained by the different learning cultures and also the language barriers. In the climate of a teacher-centered education, students are supposed to be 
quiet and be good listeners (Nguyen, Terlouw, \& Pilot, 2006). In addition, students are mainly learners, while in the student-centered education, students are more active, and teachers act more as supervisors and promote students' independence and autonomy (Elmgren \& Henriksson, 2014; Nguyen et al., 2006). Teacher-centered education is practiced in most of the South East Asian countries imbued by a "Confucian Heritage Culture" (Jin \& Cortazzi, 2006; Kennedy, 2002; Nguyen et al., 2006). In this academic culture, a teacher is considered to play the most important role, and students only speak out if they are called upon, or if they are absolutely sure that they are correct and not giving a wrong answer (Corcoran, 2014; Nguyen et al., 2006). Talking too much is considered as wasting the time of the teachers and other students, and providing wrong answers in the classroom is associated with the sense of humiliation and "losing face" in front of the classmates (Corcoran, 2014; Flowerdew, 1998; Jian, 2009; Jin \& Cortazzi, 2006; Kennedy, 2002; Nguyen et al., 2006; Starr, 2012). In this way, teachers are responsible for providing all the correct answers to the students, and they are seen as the main respectful source of information in the classroom. If students share their ideas and knowledge in the classroom, they are indirectly questioning the authority of the teachers and their knowledge. Thus, staying quiet in the classroom and not making any comments are considered as an appropriate behavior of a good and motivated student. While, as this study results have showed, this kind of behavior in the international classroom is interpreted by the teachers and the local students differently, and instead is considered as a general lack of motivation or ignorance.

Furthermore, the result of this literature review study also revealed that a negative attitude mainly towards some international students is due to their lack of equal contribution to group work. Although language barriers can explain part of this lack of participation, it also needs to be considered as an aspect of "Confucian Heritage Culture" that people play different roles when it comes to the group work. The group work should not be distributed equally, since each group has a leader that takes more responsibility than the others. Without a leader, the group cannot exist and function well (Nguyen et al., 2006). On the contrary, in the western classroom, the students are supposed to take equal responsibility and participate equally in the group work. Some of the negative experiences or stereotypes toward Asian students can be explained by the lack of knowledge about the existence of different pedagogical cultures than the western one. These academic cultural differences can lead to misunderstandings and misinterpretations of the academic ability of some students who are not familiar with the new learning environment, by labeling them as a "passive learner" or a "rote learner” (Starr, 2012; Tavakol \& Dennick, 2010). 
Another negative experience and stereotype that appeared in this study is about the concept of plagiarism. Although this issue may be related to the low language proficiency of the non-English speaking students, the lack of education about writing a scientific essay, and/or having different approaches about citation and referencing, may play an important role as well (Chien, 2014). For some students, rephrasing the original text is a disgraceful act and shows a lack of loyalty to the original author's idea (Chien, 2014). In this case, the teachers should consider that the student might not have had intent to cheat when they do not take the necessary precautions of having appropriate citations and referencing styles. They might just be following the instructions that they learned in their home country (Chien, 2014). Therefore, it is important that teachers make sure that there is a same level of understanding among all the students in the international classroom, especially regarding the concept of plagiarism before asking them to write any scientific text.

This literature review study addressed some of the challenges that teachers and students may experience in the international classroom. Contiguous with the above-mentioned issues, it is also notable that teaching and learning in the international classroom also improved the cultural and educational competence of the teachers and the students, and also many of the negative experiences dissolved after the students adjusted to the new academic environment. However, more research needed to focus on coping strategies in the international classroom related to teaching and learning development.

Finally, familiarizing students with the prevailing pedagogical strategies, academic cultures, and teaching styles (Kennedy, 2002), as well as increasing the cultural awareness of the teachers (Eaves, 2011; Flowerdew, 1998; Tavakol \& Dennick, 2010) would result in respectful and friendly learning environments with clear structure and constructive feedback (Elmgren \& Henriksson, 2014; Nguyen et al., 2006), and focusing on learning outcomes rather than learning behaviors is recommended as a strategy that can increase the chances of achieving the study objective, which in turn and can reduce the risk of misunderstandings in the international classroom. It is also recommended that using visual teaching tools can be helpful when there is a language barrier or when it comes to describing complex technical concepts (Nguyen et al., 2006).

It needs to be acknowledged that the results of this paper are based on studies using a qualitative approach and the subjective experiences of individuals. Thus, the results cannot be generalized to international students in general or classroom experiences using English as medium of instruction in particular. It would also be interesting to see other studies among the experience of "English speaking" or "European" students in the international classroom, since the included articles in this study were mostly 
directed toward Asian students who did their studies in western universities. The authors also recommend more studies that investigate the similarities or differences in the educational culture rather than investigating and highlighting the differences only, which can increase the risk of stereotypes and ethnocentrism.

\section{CONCLUSION AND IMPLICATIONS}

This study investigated the experience of teaching and learning in the international classroom from the perspective of teachers, international students, and host students. Although language barrier was identified as one of the main variables, which were addressed both by the teachers and the students, it seems that academic cultural differences also play a very important role. Students and teachers with different learning and teaching experiences have different expectations from each other, which can potentially impact on the learning outcomes in the international classroom. This can also lead to a negative experience and foster a stereotypical view of certain students based on their educational behaviors. Although a more flexible pedagogical method in the international classroom is recommended, more interventional research is necessary to address the clear and comprehensive pedagogical strategies in the international classroom when language barriers and cultural differences exist. Further, focusing on pedagogical strategies and being aware of different teaching and learning method can reduce the risk of misunderstandings, which in turn can lead to improve learning outcomes for international students.

\section{REFERENCES}

Akli, M. (2013). Study abroad and cultural learning through Fulbright and other international scholarships: A holistic student development. Journal of International Students, 3(3), 1-9.

Bamford, J. (2008). Strategies for improving international students' academic and cultural experiences of UK study. In R. K. Atfield, Patsy (Ed.), Enhancing the International Learning Experience: in Business and Management Hospitality Leisure Sport and Tourism (pp. 58-67). Newbury, UK: Threshold.

Brunton, M., \& Jeffrey, L. (2014). Identifying factors that influence the learner empowerment of international students. International Journal of Intercultural Relations, 43, 321-334. doi: 10.1016/j.ijintrel.2014.10.003

Chien, S.-C. (2014). Cultural Constructions of Plagiarism in Student Writing: Teachers' Perceptions and Responses. Research in the Teaching of English, 49(2), 120.

Cooper, H. (2016). Research synthesis and meta-analysis: A step-by-step approach (Vol. 2): Sage publications.

Corcoran, C. (2014). Chinese learning styles: Blending Confucian and Western theories. Journal of Instructional Pedagogies, 13, 1. 
Cruickshank, K., Chen, H. L., \& Warren, S. (2012). Increasing international and domestic student interaction through group work: a case study from the humanities. Higher Education Research \& Development, 31(6), 797-810. doi: 10.1080/07294360.2012.669748

Davis, M. (2012). International postgraduate students' experiences of plagiarism education in the UK: Student, tutor and expert perspectives. International Journal for Educational Integrity, 8(2), 21-33.

Eaves, M. (2011). The relevance of learning styles for international pedagogy in higher education. Teachers and Teaching, 17(6), 677-691.

Elmgren, M., \& Henriksson, A.-S. (2014). Academic teaching. Lund: Studentlitteratur.

Evans, C., \& Stevenson, K. (2011). The experience of international nursing students studying for a PhD in the U.K: A qualitative study. BMC Nurs, 10, 11. doi: 10.1186/1472-6955-10-11

Flowerdew, L. (1998). A cultural perspective on group work. ELT journal, 52(4), 323-329.

Foster, K. D., \& Stapleton, D. M. (2012). Understanding Chinese Students' Learning Needs in Western Business Classrooms. International Journal of Teaching and Learning in Higher Education, 24(3), 301-313.

Gram, M., Jaeger, K., Liu, J. Y., Qing, L., \& Wu, X. Y. (2013). Chinese students making sense of problem-based learning and Western teaching - pitfalls and coping strategies. Teaching in Higher Education, 18(7), 761-772. doi: 10.1080/13562517.2013.836096

Harrison, N., \& Peacock, N. (2009). Interactions in the international classroom-The UK perspective In J. Elspeth (Ed.), Internationalisation and the student voice: Higher education perspectives (pp. 125-142). London: Routledge.

Harrison, N., \& Peacock, N. (2010). Cultural distance, mindfulness and passive xenophobia: using Integrated Threat Theory to explore home higher education students' perspectives on 'internationalisation at home'. British Educational Research Journal, 36(6), 877-902.

Hughes, H., \& Bruce, C. S. (2013). International students' experiences of informed learning: A pedagogical case study. International Journal of Pedagogies and Learning, 8(2), 106-119.

Jackson, M. R., Sukanya; Bybell, Danica (2013). International Students in the United States: Social and Psychological Adjustment. Journal of International Students, 3(1), 17-28.

Janjua, F., Malik, S., \& Rahman, F. (2011). Learning Experiences and Academic Adjustment of International Students: A Case Study from Pakistan. Journal of Language Teaching and Research, 2(6), 1359-1365.

Jian, H. (2009). A contrastive study of cultural diversity of learning styles between China and the United States. International Education Studies, 2(1), p163.

Jin, L., \& Cortazzi, M. (2006). Changing practices in Chinese cultures of learning. Language, Culture and Curriculum, 19(1), 5-20.

Jongyeon, E. (2013). “He’s an idiot!” Experiences of International Students in the United States. Journal of International Students, 3(1), 72-75.

Kennedy, P. (2002). Learning cultures and learning styles: Myth-understandings about adult (Hong Kong) Chinese learners. International journal of lifelong education, 21(5), 430-445. 
Kerdchoochuen, J. (2011). Speaking With A Stranger: Intercultural Classrooms’ Tensions And Managing Strategies. Journal of College Teaching \& Learning, 8(9), 9-17.

Khozaei, F., Naidu, S., Khozaei, Z., \& Salleh, N. A. (2015). An exploratory study of factors that affect the research progress of international $\mathrm{PhD}$ students from the Middle East. Education and Training, 57(4), 448-460. doi: 10.1108/Et09-2013-0115

Kim, H. Y. (2011). International graduate students' difficulties: Graduate classes as a community of practices. Teaching in Higher Education, 16(3), 281-292.

Kim, J., Tatar, B., \& Choi, J. (2014). Emerging culture of English-medium instruction in Korea: experiences of Korean and international students. Language and Intercultural Communication, 14(4), 441-459.

Kumi-Yeboah, A., \& James, W. (2014). Transformative Learning Experiences of International Graduate Students From Asian Countries. Journal of Transformative Education, 12(1), 25-53.

Marton, F., \& Booth, S. A. (1997). Learning and awareness: Psychology Press.

Mukminin, A., \& McMahon, B. J. (2013). International Graduate Students' CrossCultural Academic Engagement: Stories of Indonesian Doctoral Students on an American Campus. The Qualitative Report, 18, 1-9.

Nguyen, P. M., Terlouw, C., \& Pilot, A. (2006). Culturally appropriate pedagogy: the case of group learning in a Confucian Heritage Culture context. Intercultural Education, 17(1), 1-19.

Otten, M. (2003). Intercultural Learning and Diversity in Higher Education. Journal of Studies in International Education, 7(1), 12-26. doi: $10.1177 / 1028315302250177$

Paris, D. (2012). Culturally sustaining pedagogy a needed change in stance, terminology, and practice. Educational Researcher, 41(3), 93-97.

Patton, M. Q. (2014). Qualitative Research \& Evaluation Methods. 2001 Sage Publications. Thousand Oaks, California.

Poyrazli, S., \& Lopez, M. D. (2007). An exploratory study of perceived discrimination and homesickness: a comparison of international students and American students. J Psychol, 141(3), 263-280. doi: 10.3200/JRLP.141.3.263-280

Rienties, B., Johan, N., \& Jindal-Snape, D. (2015). Bridge building potential in cross-cultural learning: a mixed method study. Asia Pacific Education Review, 16(1), 37-48. doi: 10.1007/s12564-014-9352-7

Roy, S. R. (2013). Educating Chinese, Japanese, and Korean International Students: Recommendations to American Professors. Journal of International Students, 3(3), 10-12.

Saravanamuthu, K., \& Yap, C. (2014). Pedagogy to empower Chinese Learners to adapt to western learning circumstances: a longitudinal case-study. Cambridge Journal of Education, 44(3), 361-384. doi: 10.1080/0305764x.2014.914154

Sawir, E. (2011). Dealing with diversity in internationalised higher education institutions. Intercultural Education, 22(5), 381-394.

Sawir, E. (2013). International Students and Internationalisation of Higher Education. Journal of International Students, 3(1), iii-iv. 
Sheridan, V. (2011). A holistic approach to international students, institutional habitus and academic literacies in an Irish third level institution. Higher Education, 62(2), 129-140. doi: 10.1007/s10734-010-9370-2

Starr, D. (2012). China and the Confucian education model. Universitas, 21(1), e27.

Tait, C. (2010). Chinese Students' Perceptions of the Effects of Western University Examination Formats on their Learning. Higher Education Quarterly, 64(3), 261-275.

Tange. (2010). Caught in the Tower of Babel: university lecturers' experiences with internationalisation. Language and Intercultural Communication, 10(2), 137-149. doi: 10.1080/14708470903342138

Tange, H., \& Jensen, I. (2012). Good teachers and deviant learners? The meeting of practices in university level international education. Journal of Research in International Education, 11(2), 181-193.

Tavakol, M., \& Dennick, R. (2010). Are Asian international medical students just rote learners? Advances in Health Sciences Education, 15(3), 369-377.

Tian, M., \& Lowe, J. (2013). The role of feedback in cross-cultural learning: a case study of Chinese taught postgraduate students in a UK university. Assessment \& Evaluation in Higher Education, 38(5), 580-598. doi: $10.1080 / 02602938.2012 .670196$

Trahar, S., \& Hyland, F. (2011). Experiences and perceptions of internationalisation in higher education in the UK. Higher Education Research \& Development, 30(5), 623-633. doi: 10.1080/07294360.2011.598452

UNESCO. (2013). The International Mobility of Students in Asia and the Pacific. Bangkok: United Nations Educational, Scientific and Cultural Organization.

UNESCO. (2014). Global flow of tertiary-level students. Retrieved 19/10/2015, from UNESCO Institute for Statistics http://www.uis.unesco.org/Education/Pages/international-student-flowviz.aspx

Valdez, G. (2015). U.S. Higher Education Classroom Experiences of Undergraduate Chinese International Students. Journal of International Students, 5(2), $188-200$.

Valiente, C. (2008). Are students using the'wrong'style of learning? A multicultural scrutiny for helping teachers to appreciate differences. Active Learning in Higher Education, 9(1), 73-91.

Van der Wende, M. (2001). The International Dimension in National Higher Education Policies: what has changed in Europe in the last five years? European journal of education, 36(4), 431-441.

Wang, Y. N. (2012). Transformations of Chinese international students understood through a sense of wholeness. Teaching in Higher Education, 17(4), 359370. doi: 10.1080/13562517.2011.641004

Wang, L., \& Byram, M. (2011). 'But when you are doing your exams it is the same as in China' - Chinese students adjusting to western approaches to teaching and learning. Cambridge Journal of Education, 41(4), 407-424. doi: 10.1080/0305764x.2011.625001

Yates, L., \& Thi QuynhTrang, N. (2012). Beyond a discourse of deficit: The meaning of silence in the international classroom. The International Education Journal: Comparative Perspectives, 11(1), 22-34. 
JALAL SAFIPOUR, PhD, is a senior lecturer in the Department of Health and Caring Sciences at Linnaeus University, Sweden. His main research field is public health and sociology of health. In last few years he is mainly teaching in the international classroom environment. Email: jalal.safipour@lnu.se

STIG WENNEBERG got his PhD in the field of physiology from Maharishi International University (now Maharishi University of Management) in USA. He is working as a senior lecture in the Department of Health and Caring Sciences at Linnaeus University, Sweden. His main research area includes: alternative medicine and health. He can be reached at: stig.wenneberg@lnu.se

EMINA HADZIABDIC, PhD, is a senior lecture and currently working as Deputy Head of the Department of Health and Caring Sciences at Linnaeus University. Her research interest includes cultural competence, ethnicity and health communication. Her email address is: emina.hadziabdic@lnu.se

Manuscript submitted: June 20, 2016

Manuscript revised: September 26, 2016 Accepted for publication: October 27, 2016 